Derecho \& Realidad

Núm. 24 • II semestre de 2014

Facultad de Derecho y Ciencias Sociales, UPTC

ISSN: 1692-3936

\title{
Vías ineficaces de exigibilidad jurídica para substanciar $y$ resolver juicios de responsabilidades $y$ sancionar delitos de lesa humanidad en el sistema jurídico boliviano
}

Ineffective way of legal enforceability to substantiate and resolve trials of liability and punish crimes against humanity in the Bolivian legal system

Misael Christian López Medina*

\section{Resumen}

El presente trabajo describe las contradicciones, vacíos y obstáculos legales que presentaron y presentan las normas jurídicas bolivianas y algunas normas internacionales, en materia de substanciación y resolución de juicios de responsabilidades por delitos de lesa humanidad, cometidos por altos dignatarios de Estado. Específicamente se pretende mostrar la ineficacia del principio de exigibilidad jurídica, dentro la substanciación y resolución del juicio de responsabilidades contra el expresidente Gonzalo Sánchez de Lozada -acusado por delitos de lesa humanidad por la masacre de octubre de 2003, en el que se ha dejado en espera a las víctimas y familiares de los muertos, quienes exigen una pronta investigación, juzgamiento y reparación de daños y perjuicios. Para nuestro cometido dividiremos el trabajo en dos fases: la primera, que abarca las primeras movilizaciones y conquistas jurídicas por subsanar defectos normativos; y la segunda, una descripción de las normas

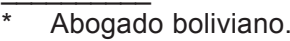


jurídicas internacionales que hacen dificil el objetivo de lograr un pronto juicio de responsabilidades; para luego aportar con ideas que puedan desempantanar este meollo jurídico.

\section{Palabras clave}

Estado, delitos de lesa humanidad, justicia, víctimas.

\section{Abstract}

This work describes the contradictions, gaps and legal obstacles that have presented the Bolivian legal rules and some international standards regarding substantiation and resolution of judgment of responsibility for crimes against humanity, committed by senior officers of State. Specifically, it aims to show the ineffectiveness of the principle of legal enforceability, in the substantiation and resolution of the trial for responsibilities against former president Gonzalo Sánchez de Lozada, -accused for crimes against humanity for the slaughter of October 2003-, leaving on hold victims and relatives of the dead who require prompt investigation and prosecution and repair damages. We divide the work in two phases: the first, covering the first demonstrations and legal conquests to remedy regulatory shortcomings and the second, a description of international legal standards that make difficult a prompt trial responsibilities, and then we provide ideas that can solve this legal problem.

\section{Keywords}

Estate, crimes against humanity, justice, victim. 


\section{Rememorando...}

En octubre de 2003, la ciudad de El Alto protagonizó jornadas de lucha y resistencia por demandas sociales nacionales contra el Gobierno de Sánchez de Lozada, rechazando sus proyectos de venta de gas a Estados Unidos vía Chile a precios bajísimos, pidiendo la recuperación de la propiedad de los hidrocarburos y la convocatoria a una Asamblea Constituyente. Lucha y resistencia que fue reprimida por el Gobierno con balas de guerra, dejando un saldo de 70 muertos y más de 400 heridos. Estos cruentos hechos provocaron la ira de la población boliviana, que se movilizó para pedir su renuncia. El 17 de octubre de 2003, Sánchez de Lozada -ante la presión social traducida en huelgas de hambre en todo el país, marchas y el cerco a la ciudad de La Paz-, renunció y abandonó el país, y se radicó en los EE.UU. Hasta el día de hoy, familiares de las víctimas y organizaciones de derechos humanos exigen un pronto juicio de responsabilidades, que no prospera por la serie de trabas jurídicas que encuentran al paso, impidiendo, de igual forma, la extradición de Sánchez de Lozada.

\section{Fase primera: exigibilidad de víctimas y familiares de los caídos de octubre por un juicio pronto al expresidente}

La primera fase del calvario de las víctimas y familiares de los caídos de octubre de 2003, empezó con las movilizaciones posteriores a la renuncia y huída del país del expresidente Sánchez de Lozada (17 de octubre de 2003), presionando y logrando que el fiscal General de República emitiera un requerimiento fiscal ante el Congreso Nacional, el 21 de noviembre del 2003, solicitando al mismo la autorización para el juicio de responsabilidades contra el expresidente Gonzalo Sánchez de Lozada, Sánchez Bustamante y su gabinete ministerial, por violación a los derechos y garantías individuales consagradas en la CPE y el Código Penal ${ }^{1}$. Pasando por las movilizaciones y marchas exigiendo al Congreso Nacional la autorización del juicio de responsabilidades ${ }^{2}$ contra el expresidente y su gabinete ministerial, que se logró el 14 de octubre de 2004, a través de la Resolución Congresal 004/04-05, autorizando a la Corte Suprema de Justicia, el juicio de responsabilidades contra el expresidente Gonzalo Sánchez de Lozada, Sánchez Bustamante y su gabinete ministerial; y concluyendo dicha primera fase con una declaración del Tribunal Constitucional en 2005 que la desarrollaremos más adelante, por ser el punto culminante de esta fase.

\footnotetext{
Artículos 6, 7, 9, 12, 13 y 21 de la Constitución Política del Estado y el articulo 138 párrafos segundo y tercero, de la ley 1970 de 25 de Marzo de 1999. Nuevo Código de Procedimiento Penal. 2 Numeral 11 del Art. 68 y atribución $5^{\text {a }}$ del Art. 118 de la Constitución Política del Estado, concordante con el párrafo cuarto del Art. 3 de la Ley No. 2445 del 13 de marzo del 2003.
} 
Ley de juicio de responsabilidades contra altos dignatarios de Estado: vacíos y contradicciones

Después de lograr la autorización congresal de juicio de responsabilidades, empezaron a surgir problemas de naturaleza jurídica: la Ley 2445 de Juicio de Responsabilidades Contra Altos Dignatarios de Estado, que lleva concordancia con la $\mathrm{CPE}^{3}$, fue promulgada el 13 de marzo de 2003, en el mismo periodo de mandato de Sánchez de Lozada, en la cual no se establecía, de forma expresa, el procedimiento y los plazos procesales aplicables para la substanciación y resolución del juicio de responsabilidades, conllevando necesariamente la búsqueda de una norma jurídica análoga (Código de Procedimiento Penal), pero, dicha Ley 2445 contiene términos ambiguos que hacen referencia a las normas del Nuevo Código de Procedimiento Penal (Ley 1970 de 25 de marzo de 1999) y las normas del Código de Procedimiento Penal abrogado (Decreto Supremo 10426 de 23 de agosto de 1972), combinando términos, como por ejemplo, "SUMARIO" ${ }^{4}$, término correspondiente al código abrogado que ordenaba a los magistrados de la Sala Penal de la Corte Suprema de Justicia (CSJ), encargarse primero de investigar a los imputados y luego pronunciarse por la acusación o sobreseimiento; contradiciendo el espíritu del nuevo Código de Procedimiento Penal, que distribuye los roles de investigación y control jurisdiccional, el primero designado al fiscal -para que en representación del Estado y la sociedad se encargue de la investigación ${ }^{5}$ - y el segundo, a la Sala Penal de la CSJ, -para actuar como controlador de las garantías constitucionales en la etapa preparatoria ${ }^{6}$.

Como salidas a la falta de definición de un procedimiento específico se propusieron varias, entre ellas: 1) La aplicación del Nuevo Código de Procedimiento Penal (NCPP) para subsanar los vacíos de procedimiento de la ley 2445, ya que con el procedimiento penal actual, el fiscal tiene amplias potestades investigativas, y se señalan plazos para las etapas del proceso, de seis meses para la investigación y tres años para conocer la sentencia. Sin embargo, la defensa de Sánchez de Lozada solicitó la nulidad de actos, con el argumento de que el proceso no se enmarca en la Constitución Política del Estado, la misma que norma el deber de la Sala Penal de la CSJ para asumir funciones en la etapa sumaria (investigativa) ${ }^{7}$. 2) La aplicación del Código de Procedimiento Penal abrogado (CPPA), el mismo que otorgaría a los jueces de la Sala Penal de la CSJ la doble atribución de investigar y condenar

\footnotetext{
Atribución $5^{\mathrm{a}}$ del artículo 118 de la Constitución Política del Estado.

4 El término SUMARIO fue también conocido con el sinónimo de INSTRUCCIÓN Art. 120, 168 del Decreto Supremo No 10426 de 23 de Agosto de 1972. Código de Procedimiento Penal Abrogado. Párrafo quinto del Art. 3 de la Ley 2445 de Juicio de Responsabilidades Contra Altos Dignatarios de Estado.

5 Artículo 70 de la ley 1970. Nuevo Código de Procedimiento Penal.

7 Art. 118 atr. $5^{\text {a }}$ Constitución Política del Estado.
} 
o sobreseer. Si ese pudo ser el caso, la defensa de Sánchez de Lozada pudo haber solicitado nuevamente la nulidad de actos, alegando vulneración de sus derechos y garantías reconocidos en la $\mathrm{CPE}^{8}$, por la no aplicación del procedimiento establecido en el NCPP a falta de individualización de funciones desconcentradas en diferentes actores como el fiscal y el juez cautelar. 3) Aplicar los dos códigos de procedimiento penal, CPPA y NCCP, para establecer las fases sumariante y plenaria ${ }^{9}$ con el primero, y dar las garantías constitucionales a los imputados con el segundo. De igual forma, pudo ser causa de impugnación por parte de la defensa de Sánchez de Lozada, al ser una decisión arbitraria librada al criterio de las autoridades, por no existir una norma establecida y escrita para conocer en qué momento se aplica el uno o el otro. 4) Solicitar al Congreso la sanción de una ley interpretativa de la Ley 2445 de Juicio de Responsabilidades. Esta medida pudo dar cierta claridad al procedimiento, pero el meollo jurídico se generó en el artículo 118 atribución 5ta de la $\mathrm{CPE}^{10}$ que preceptúa términos ambiguos, por tanto, su interpretación debía ser dada por el órgano constitucional, ya que cualquier intento de solución hubiera llevado a dotar a la defensa de elementos de impugnación del proceso.

En junio de 2005, el Tribunal Constitucional emitió una declaración constitucional ${ }^{11}$ que resolvió declarar la CONSTITUCIONALIDAD del artículo 393 del NCPP ${ }^{12}$ y del párrafo $5^{\circ}$ inciso I del artículo 3 de la Ley 2445. El artículo 393 sostiene que para el juzgamiento de altos dignatarios de Estado por delitos cometidos en el ejercicio de sus funciones, se aplicarán las normas del juicio oral y público establecidas en el NCPP. Además realiza interpretaciones de la norma aplicable en la etapa preparatoria, en este caso las correspondientes al NCCP. Con la Declaración Constitucional de 2005 se resolvieron los problemas de aplicación e interpretación de la ley aplicable a los juicios de responsabilidad.

\section{Fase segunda: exigibilidad de víctimas y familiares de los caídos de octubre por el juicio pronto al expresidente}

Desde la fecha hasta hoy se tropieza con obstáculos legales de orden internacional con sus inmediatos efectos de orden interno: 1) La Corte Suprema de Justicia,

\footnotetext{
Inc. IV del Art. 16 y Art. 124 Constitución Política del Estado. Libro Tercero del Código de Procedimiento Penal abrogado.

10 En su texto preceptúa: CSJ: fallar en juicios de responsabilidad contra Altos Dignatarios de Estado, a requerimiento del Fiscal, previa autorización el Congreso Nacional, en cuyo caso el sumario estará a cargo de la Sala Penal de la CSJ, y si ésta se pronuncia por la Acusación el juicio se substanciará por las demás salas.

11 Declaración Constitucional 0003/2005 de 8 de junio de 2005.

12 Privilegio Constitucional.- Para el juzgamiento de los funcionarios públicos comprendidos en el art. 66 numeral 1) y artículo 118 numerales 5) y 6) de la Constitución Política del Estado, por delitos cometidos en el ejercicio de sus funciones, se procederá con arreglo a lo previsto en la Constitución Política del Estado, siendo aplicables las normas del juicio oral y público establecidas en este Código".
} 
mediante la Cancillería de la República, envió un exhorto suplicatorio a EE.UU., el cual, según se tiene conocimiento, se encuentra en poder del Departamento de Justicia de los EE.UU., desde donde debe enviarse la citación con el requerimiento acusatorio para que comparezca ante las autoridades jurisdiccionales bolivianas, pero el Gobierno norteamericano guarda silencio y no da claras explicaciones del porqué no se citó al expresidente hasta la fecha, favoreciendo al expresidente en el cómputo de la prescripción de la acción punitiva del Estado, como lo señala el artículo 4 de la Ley $2445^{13}$ en relación con el artículo 90 del NCCP, que para el caso del expresidente sería de ocho años, desde fenecida su función pública ${ }^{14}$;2) Si se lograra citar a Sánchez de Lozada, y no compareciera, la declaratoria de rebeldía interrumpiría la prescripción, pero si fuera declarada en el juicio oral (después de la etapa investigativa $=$ sumaria) el juicio se suspendería con respecto al rebelde ${ }^{15}$, lo que implica que es necesario solicitar la extradición al Estado norteamericano; pero, según el Tratado de Extradición entre Bolivia y Estados Unidos de 27 de junio de $1995^{16}$, la extradición procede por una serie de delitos, y lo irónico es que no se enuncia de forma expresa el delito de genocidio, delito principal por el cual se dictaminó un requerimiento acusatorio. A esto se suma otro problema, pues con relación a los delitos no enunciados, la autoridad del Estado requerido (EE.UU.) podrá denegar la extradición, por la razón de ser la persona reclamada nacional del Estado requerido ${ }^{17}$; en este punto no se tiene conocimiento oficial si Sánchez de Lozada posea la nacionalidad boliviana o americana. 3.-) Tampoco se concedería la extradición si el delito por el cual se le ha solicitado es de carácter político ${ }^{18}$, y en las declaraciones que el expresidente realiza a los medios de comunicación americanos señala que el proceso que se le sigue en el país es de carácter político.

\section{Conclusiones}

- La tutela de los bienes jurídicos de las personas y la lucha contra los delitos de lesa humanidad y de cuello blanco en Bolivia, precisa un procedimiento penal ajustado a la realidad del país; de lo contrario, la ley conduce a los imputados a una irresponsabilidad penal e impunidad.

- Sobre la prescripción de la acción, sin duda el artículo 4 de la Ley 2445 contradice las normas de la Convención sobre Imprescriptibilidad de los Crímenes de Guerra

13 Art. 4 de la Ley 2445. "El Juicio de Responsabilidades por la comisión de los delitos tipificados prescribirá conforme lo establece el Artículo $29^{\circ}$ del Código de Procedimiento Penal.

14 Calculando el cómputo de la prescripción de acción desde el 17 de octubre hasta la fecha sería de cuatro años y cuatro meses.

15 Art. 90 del Código de Procedimiento Penal.

16 Tratado de Extradición entre Bolivia y Estados Unidos de 27 de junio de 1995.

17 Num. 12 Art. III Tratado de Extradición entre Bolivia y Estados Unidos de 27 de junio de 1995.

18 Num. 1 Art. V Tratado de Extradición entre Bolivia y Estados Unidos de 27 de junio de 1995. 
y Lesa Humanidad ${ }^{19}$ de la cual Bolivia es signatario; sin embargo, esta contradicción se supera con la aplicación del artículo 27 de la Convención de $V_{\text {Viena }}{ }^{20}$, según la cual "una parte no podrá invocar las disposiciones de su derecho interno como justificación del incumplimiento de un tratado".

- La ley 2445 de Juicio de Responsabilidades, da lugar a pensar que esta norma jurídica fue deliberadamente aprobada con el objeto de otorgar impunidad a las más altas autoridades de Gobierno.

- Urge la creación de una ley de Juicio de Responsabilidades que de manera expresa y exhaustiva establezca los alcances de este procedimiento especial, con el fin de superar estos obstáculos legales.

- Es necesario constitucionalizar la imprescriptibilidad de las acciones penales por los delitos de lesa humanidad.

- Determinar, inequívocamente mediante ley, a los altos dignatarios de Estado en el ejercicio de sus funciones como sujetos pasivos del procedimiento especial, y no aquellos que han cesado ya en sus funciones que deben someterse a la jurisdicción ordinaria.

19 Convención sobre la Imprescriptibilidad de los Crímenes de Guerra y de los Crímenes de Lesa Humanidad, aprobada por la resolución 2391 de la Asamblea General de la ONU el 26 de noviembre de 1968.

20 Convención de Viena sobre el Derecho de los Tratados, Viena, 23 de mayo de 1969. 